DOI 10.37882/2223-2982.2021.11-2.30

\title{
ОБРАЗ «УЧИТЕЛЬ/教师» В ЯЗЫКОВОМ СОЗНАНИИ КИТАЙЦЕВ И РУССКИХ (НА МАТЕРИАЛАХ АССОЦИАТИВНЫХ ПОЛЕЙ)
}

\section{THE IMAGE OF THE "TEACHER/教师" IN THE LANGUAGE CONSCIOUSNESS OF CHINESE AND RUSSIAN (OH THE MATRIALS OF ASSOCIATIVE FIELDS)}

\section{Jia Shuyue}

Yan Lei

Summary: The article discuss the image of the profession-teacher in the language consciousness of the Chinese and Russian students. Conducts free associative experiment with the stimulus-teacher/教师 and statistical analysis of the data. Identify the similarities and differences in the content and structure of associative field in which contained language consciousness, and their ethnocultural specifics.

Keywords: image of the profession-teacher, language consciousness, free associative experiment, associative field, ethnocultural specifics.

\section{Введение}

Московская психолингвистическая школа давно обратила особое внимание на исследование языкового сознания. В 1988 г. Е.Ф. Тарасовым впервые было выдвинуто понятие «языковое сознание» и определено как «образы сознания, овнешняемые языковыми знаками» [2, с. 10]. Т.е. как «образы сознания, овнешняемые языковыми средствами: отдельными лексемами, словосочетаниями, фразеологизмами, текстами, ассоциативными полями и ассоциативными тезаурусами как совокупностью этих полей» [3]. Согласно Н.В. Уфимцеву, языковое сознание рассматривается как «средство познания чужой культуры в её предметной, деятельностной и ментальной форме, а также как средство познания своей культуры» [5, c. 207]. Русский и китайский языки, как морфологически разные системы, отражают языковое сознание разных носителей. Профессии являются значительной частью человеческой общественной жизни. Образ профессии представляет собой «целостное отображение основного содержания профессии» [1].

По мнению Н.В. Уфимцевой и Е.Ф. Тарасова, «индивидуальное сознание каждого члена общества заполнено знаниями, которые являются для всех носителей конкретного этнического языка и культуры в такой степени общими» $[6$, с. 18]. Таким образом, для одной страны и одного народа существуют как изменения знаний о разных профессиях в синхронии, так и изменения представлений об одной и той же профессии в различные
Цзя Шуюе

Аспирант, Институт языкознания РАН 1041487637@q9.com

Янь Лэй

Преподаватель, Харбинский педагогический университет yl19920310@126.com

Аннотация: В данной статье рассматривается образ профессии учителя в языковом сознании китайцев и русских, даётся описание хода свободного ассоциативного эксперимента со словом-стимулом - учитель/教师, анализируются полученные данные, выявляются сходство и различия в содержании и структуре ассоциативных полей, и их этнокультурная специфика.

Ключевые слова: образ профессии учителя, свободный ассоциативный эксперимент, ассоциативное поле, ассоциативное поле, этнокультурная специфика.

эпохи. В одном и том же историческом периоде для разных стран и регионов существуют различия и сходство в суждениях о содержании и отношении к одной и той же профессии. Именно эти различия отражают значительные изменения представлений о профессии и профессиональных ценностях. Следовательно, можно предположить, что название профессии - это своеобразный языковой маркер, с которым связаны в языковом сознании носителей определенного языка и культуры представления о профессиях. Носители разных языков могут иметь разное представление об одной и той же профессии по причине различий в культуре и национальном менталитете.

Одним из эффективных методов изучения и моделирования языкового сознания носителя языка, и описания процессов ассоциирования в современных психолингвистических исследованиях является ассоциативный эксперимент, который даёт «возможность выявить как системность содержания образа сознания, стоящего за словом в той и или иной культуре, так и системность языкового сознания носителей той или иной культуры как целого и показывают уникальность и неповторимость образа мира каждой культуры» [Уфимцева 2011:207]. Следовательно, мы попытаемся описать и проанализировать представление о профессии учитель в языковом сознании китайцев и русских посредством свободного ассоциативного эксперимента. А также выявить этнокультурную специфику языкового сознания носителей русского и китайского языков. 
Целью исследования является выявление сходств и различий в представлениях о профессиях в языковом сознании носителей китайского и русского языков.

Гипотеза исследования: содержание представлений о профессии учителя в языковом сознании носителей китайского и русского языков имеет черты сходства и различия, обусловленных этнокультурной спецификой их языкового сознания.

Ход эксперимента. В 2018 г. в Китае был проведен свободный ассоциативный эксперимент с носителями китайского языка, для которых китайский язык является родным. Опрос был произведен на китайском языке В письменной форме через интернет. С самого начала эксперимента экспериментатор объяснил испытуемым цели проведения исследования. Испытуемым были предложены анкеты на китайском языке, они должны были написать первое слово (словосочетание/предложение), пришедшее в голову как ответ на каждое слово-стимул. Испытуемые должны были отвечать самостоятельно, запрещалось обращаться за помощью к посторонним и пользоваться словарем. На запись каждого слова-реакции отводилось не более 10 секунд. В ходе эксперимента всего было заполнено 900 анкет, из которых 823 были признаны валидными. В качестве программного обеспечения для статистической обработки экспериментальных данных использованы SPSS версии 19 и Microsoft Excel 2003.

Испытуемые. В свободном ассоциативном эксперименте приняли участие 823 китайских испытуемых различных специальностей из разных университетов KHP: Харбинского педагогического университета - 457 студентов (г. Харбин), Хубэйского гуманитарного и естественного университета - 23 студента (г. Сянян), Цзинаньского университета - 16 студентов (г. Гуанчжоу), Хубэйского университета - 12 студентов (г. Вунан), Хэнаньского педагогического университета - 11 студентов (г. Синьсян), Северо-восточного лесоводческого университета - 9 студентов (г. Харбин), Северо-восточного педагогического университета - 9 студентов (г. Харбин), Хубэйского технологического университета - 23 студента (г. Сяньнин) и др. Из них 334 (40.6\% от общего числа студентов) и 489 женщин (58.8\% от общего числа студентов). Среди испытуемых самая многочисленная группа студенты первого курса. Она составляла $38.5 \%$ от общего числа. Группа студентов второго курса составила $28.6 \%$. Группа магистров - 15.1\%, группа студентов четвёртого курса - $11.7 \%$. Группа студентов третьего курса составила $6.2 \%$ от общего числа.

Списки названий профессий. Списки-стимулы названий профессий взяты из данных опроса «Самые счастливые профессии в Китае» 2016 г. и традиционная иерархия профессий таких, как рабочий, крестьянин, военный, ученый, бизнесмен. Из этих списков, по результатам пилотажного эксперимента, были отобраны 16 слов-стимулов: врач, учитель, госслужащий, военный, журналист, артист, рабочий, крестьянин, бизнесмен, полицейский, юрист, писатель, инженер, спортсмен, космонавт, ученый. В данной статье мы взяли в качестве примера ассоциативное поле «Учитель/教师» у китайцев и русских. Необходимо отметить, что в настоящее время КНР находится на стадии стремительного развития, и все общество культивирует и соблюдает основные социалистические ценности. Одновременно с этим постепенно возникают негативные ценности, такие как индивидуализм, гедонизм, вещизм и др. Вместе с изменением социальных и профессиональных ценностей появляются негативные явления, такие как плата за дополнительный урок, которую берет учитель, наказания учеников, «красные конверты» для врача и др. Таким образом, мы обращаем внимание на исследование сходства и различий представления о профессии учителя в языковом сознании китайцев и русских.

\section{Анализ ассочиативных полей «Учите^ь/教师»}

Ассоциативное поле «Учитель» для русских было нами взято из ассоциативного словаря «Русский ассоциативный словарь» (1996) (см.таб.1). В результате САЭ был получено ассоциативное поле слова-стимула «Учитель/ 教师» (см.таб.2).

Ассоциативное поле «Учитель/教师» русских

Таблица 1.

Учитель: истории 6; математики 4; добрый, музыки, мучитель, пения, рисования 3; друг, женщина, злой, любимый, мой, первый, плохой, преподаватель, русского, словесности, указка, ученик, хороший 2; авторитет, азбука, алгебры, английского, баба, ботаники, в школе, все, географии, говорит, двоечник, дирижер, достал, дурак, зануда, занятие, Ирка, история, класс, классный, кусок, литература, мужчина в сером костюме, мученик, наставник, не всегда человек, немецкого, немецкого языка, Орлов, отец, пение, пенсне, прав, прекрасный, пришел, само, сердечный, скучно, спрашивает, стоит, строгий, учитель, физики, химии, хлястик, человек, школа, шпион, язык $1 ; 102+70+2+49$

Был проведен сопоставительный анализ данных ассоциативных полей слов-стимулов «Учитель/教师», основанный на девяти аспектах:

1. Общие сходства и различия. В ассоциативных полях слов-стимулов «Учитель/教师» у русских и китайских испытуемых появились тождественные реакции: ученик/学生 $(2,181)$, преподаватель/教 师 $(2,3)$, 教鞭/указка $(2,2)$. Эти слова-реакции указывают на то, что в языковом сознании носителей китайского и русского языков имеется сходство в образе учителя. Следует отметить, что общих реакций у русских и китайских испытуемых относительно меньше, что, с другой стороны, обозначает большую разницу в их языковом сознании. 
教师/Учитель: 学生/ученик 181; 教书/преподавать 50; 育人/воспитывать 43; 黑板/доска 41; 粉笔/мел 37; 教书育人/преподавать и воспитывать 33; 讲台/трибуна 31; 园丁/садовник 28; 上课/посещать занятие, 学校/школа 18; 讲课/проводить занятие, 教学/обучение 12; 书/книга 11; 教育/0бразование, 书本/книга 10; 蜡烛/свеча, 眼镜/0чки, 作业/домашнее задание 8; 老师/преподаватель, 辛苦/тяжелый 7; 补课/проводить дополнительное занятие, 高尚/благородный, 敬业/преданность делу, 神圣/священный, 知识/знание 5; 教人/учить людей, 教室/аудитория, 无私奉献/6ескорыстно посвящать, 严厉/строгий 4; 传道授业/учить истине и передать знания, 孩子/дети, 教师/учитель, 课本/учебник, 为人师表/быть примером для людей, 无私/бескорыстный, 尊敬/уважать 3; 传道授业解惑/учить истине, передать знания и развеять сомнения, 都敏俊/Доу Миньцзюнь, 烦人/раздражающий, 粉刺/прыщ, 奉献/посвящать, 哈师大/Харбинский педагогический университет, 和蔼/дружелюбный, 红烛/красная свеча, 教鞭/указка, 教科书/учебник, 教课/проводить занятие, 教授/профессор, 教育人/воспитывать людей, 戒尺/линейка для наказания учеников, 累/усталый, 灵魂/ душа, 没钱/безденежный, 轻松/легкий, 师德/преподавательская этика, 桃李/персики и сливы (обр. в знач.: ученики-последователи), 桃李满天下/ ученики и последователи имеются повсюду, 天使/ангел, 我/я, 误人子弟/давать ложные знания, 鲜花/свежие цветы, 幸福/счастье, 学习/учеба, 严肃/ серьезный, 责任/ответственность, 政治/политика, 职业/профессия, 制服/форма 2; teacher/учитель, 爱岗/любящий свое дело, 爱生/любить учеников, 爱心/любящее сердце, 安逸/расслабленный, 班主任/классный руководитель, 板登скамья, 备课/готовиться к уроку, 背书/читать т0, что прошло на уроке наизусть, 笔/кисть, 布置作业/задавать домашнее задание, 崇高/благородный, 传授解惑/передать знания и развеять сомнения, 传授知识/ передавать знания, 打人/ударить человека, 待遇/вознаграждение, 戴眼镜/надевать очки, 道德/нравственность, 多媒体/мультимедиа, 罚站/стоять в наказание, 繁忙/загруженный, 父母/родители, 付出/отдать, 高中老师/учитель средней школы старшей ступени, 工程师/инженер, 公仆/слуга народа, 公务员/госслужащий, 规矩/правила, 棍子/палка, 和谐/ гармония, 黑色/черный, 化学课本/учебник по химии, 话唠болтун, 欢快/веселый, 回 忆/вспоминать, 假期/каникулы, 假期多/много каникул, 教/обучать, 教案/проекты учебных планов, 教导主任/заведующий учебной частью, 教师节 День учителя, 教学生/учить учеников, 姐姐/старшая сестра, 就那样的人/такой вид людей, 考试/экзамен, 课堂/аудитория, 腊梅/химонант скороспелый, 蜡炬成灰泪始干/слезы воска на свече высыхают лишь после того, как свеча сгорит, 滥用/злоупотреблять, 老/старый, 老头/старик, 良心/совесть, 灵魂工程师/инженер человеческой души, 楼盘/стройка, 绿色的黑板/зеленая доска, 啰嗦/многословный, 忙/занятый, 没前途/бесперспективный, 没啥感觉/нет никаких ощущений, 美丽/красный, 耐心/терпение, 女/женщина, 女的/женский, 批改作业/проверять домашнее задание, 品德高尚/с высокими моральными качествами, 勤劳/трудолюбивый, 清闲/праздный, 请家长/вызов родителей, 人类精神的工程师/инженер человеческих духов, 人类灵魂工程师/инженер человеческих душ, 人民/народ, 人生导师/научный руководитель жизни человека, 软尺/сантиметр (портновский), 弱势群体/социально незащищенные слои населения, 嗓子疼/боль в горле, 上学/ходить на занятия, 生气/злиться, 手/рука, 数学/математика, 说/ говорить, 丝袜/шелковые носки, 送礼/делать подарки, 陶行知/Тао Синчжи, 讨厌/ненавидеть, 体面/престиж, 同学/однокашник, 秃顶/лысина, 王 丽/Ван Ли, 微笑/улыбка, 为灵魂做贡献/ вносить вклад в развитие души, 稳定但是我不太想当/стабильная работа, но я не хочу быть, 窝心/темный, 喜欢/нравиться, 闲/незанятый, 像麻麻/похожа на маму, 小学/начальная школа, 小学生/младшеклассники, 心灵的建筑师/архитектор умственных способностей, 辛勤园丁/старательный садовник (учитель начальных классов), 行为世范/нормы поведения, 凶狠的小学老师/злобный учитель начальных классов, 学识/знания, 学问/образованность, 学子/ученик, 严格/строгий, 衣冠离兽/зверь в человеческом облике, 悠闲/спокойный,员工/ работник, 责任感/чувство ответственности, 责任心/чувство ответственности, 挣钱/зарабатывать, 知识分子/интеллигент, 职工/персонал, 指导人/ управляющий, 制服/форма, 助人/помогать другим, 赚钱/ зарабатывать деньги, 楟谆教海/сердечное наставление 1; 823+186+0+117

2. Высокочастотные реакции. В ассоциативных полях слова-стимула «Учитель/教师» первые пять высокочастотных слов-реакций у китайских испытуемых встречаются 352 раза (42,8\% от общего числа реакций). В том числе, 学生/ученик 181, 黑 板/доска 41, 粉笔/мел 37 являются парадигматическими. 教书/npenодавать 50, 育人/воспитывать 43 являются синтагматическими. У русских истории 6, математики 4, добрый 3, музыки 3 являются синтагматическими; мучитель 3 - парадигматический, всего 19 раз (18,6\% от общего числа реакций).

3. Лицо, ассоциируемое с Учителем. В ассоциативных полях слов-стимулов «Учитель/教师» у китайских и русских испытуемых появились многие слова-реакции, касающиеся лиц, связанных с учителем. Реакция ученик/学生 $(181,2)$ встречается как у китайских испытуемых, так и у русских. Реакция ученик/学生181 - самая высокочастотная реакция, входящая в ядро АП китайцев. Можно сказать, что в языковом сознании носителей рус- ского и китайского языков учитель и учебник как два самых важных образа в учебе тесно взаимосвязаны. Реакция 教师/nреподаватель у китайских и русских испытуемых относится к ассоциации «синонимы».

Для китайцев Учитель/教师 - это 园丁/садовник 28 с положительным оттенком входит в ядро АП китайцев с 8-ым рангом. Стоит отметить, что в китайском традиционном мировоззрении существует такой устойчивый образ: учитель представляет собой трудолюбивого садовника, а студенты - это цветы Родины, которые выращиваются садовником. В этом, на наш взгляд, проявляется этнокультурная специфика представления о профессии учителя в языковом сознании китайцев. Интересно, что в русском языковом сознании представление о профессии учителя имеет оппозицию друг 2 и мучитель 2. А для китайцев Учитель/教师- это 天使/ангел 2 с положительным оттенком. У китайцев с Учителем/教师 связаны такие люди: 孩子। ребёнок 3，教授/nрофессор 2, 灵魂工程师/инженер 
человеческих душ 1 и др., у русских - двоечник, дирижер, наставник.

4. Конкретные предметы. В ассоциативных полях слов-стимулов «Учитель/教师» у китайских и русских испытуемых выходит тождественная реакция: 教鞭/указка, являющаяся учебным инструментом. У китайцев с 教师/учителем связана серия атрибутов: 粉笔/ мел 37, 讲台/трибуна 31, 眼 镜очки/ 8, 作业/домашнее задание 8, 戒尺/линейка для наказания учеников 2, 鲜花/свежие цветы 2 и др. Среди них, реакции: 粉笔/ мел 37 и 讲台/mpuбуна 31 как необходимые компоненты в процессе обучения учителя, они входят в ядро АП китайцев с 5-ым рангом и с 7-ым рангом соответственно. Интересно, что в китайском языковом сознании 眼镜/очки 8 являются важным атрибутом внешнего вида учителя. Реакция 戒尺/линейка для наказания учеников 2 - это одна из указок, используемых с древних времен в Китае. Такое устаревшее название с китайской этнокультурной спецификой также сохранилось в представлении о профессии учителя в языковом сознании китайцев.

Нужно отметить, что для китайцев 教师/Учитель ассоциируется со 蜡烛/свечой 8; с 红烛/красной свечой 2, 桃李/персиковым деревом и сливовым деревом 2, которые относятся к метафорам. Реакция 蜡烛/свеча взята из стихотворения «ВуТи/без заглавия» (Тан 848) Ли Шанинь (поэт, 813-858): «Нить шелкопряда обрывается только с его смертью; слезы воска на свече высыхают лишь после того, как свеча сгорит». В наше время слова «свеча» и «красная свеча» используются для похвалы учителя за его бескорыстную жертвенность. Следовательно, эти реакции с национально-культурной спецификой укоренились в сознании китайцев, потому что «в основе каждой культуры лежит своя система предметных значений, социальных стереотипов, когнитивных схем» [4, с. 8]. Реакция 桃李/персиковое дерево и сливовое дерево исходит из книги «Цзы чжи тун цзянь», которую написал Сыма Гуан (Сун, 1019-1086), выпущенной в 1804 г. 桃李/персиковое дерево и сливовое дерево 2 в данный момент не обозначает дерево, а подразумевает учеников. Подобные метафорические реакции у русских отсутствуют.

У русских испытуемых встречаются слова-реакции: истории 6, математики 4, музыки 3, рисования 3, словесности 2, алгебры 1, географии 1, русского 2, английского 1, немецкого 1 и др., связанные с конкретными дисциплинами. Слова-реакции истории 6, математики 4 входят в ядро ассоциативного поля русских с 1-ым и 2-ым рангом. Из этого видно, что русские уделяют внимание ассоциациям конкретной профессии учителя.

5. Профессиональная деятельность. Одной из отличительных особенностей является то, что в ассоциативном поле слова-стимула «Учитель/教师» у китайских испытуемых встречаются реакции 教 书/nреподавать 50, 育人воспитывать 43, 上课 проводить занятия 18, 讲课/nреподавать 12, 补 课/nроводить дополнительное занятие 5, 教人 обучать людей 4, связанные с профессиональной деятельностью учителя. Среди них, реакции 教 书/npenодавать 50, 育人вoсnumывать 43 входят в ядро АП китайцев с 2-ым и с 3-им рангом соответственно. Реакция 教书育人/npenoдавать и воспитывать 33 как долг учителя, входит в ядро АП китайцев с 6-ым рангом. Реакции 传道 授业/учить истине и передать знания 3 и 传道授 业解惑 учить истине, передать знания и развеять сомнения 2, заимствованы из исторического произведения Хан Юй (Тан 768-824) и являются типичными китайскими представлениями об учителе. Фразеологизм-реакция 误人子弟/давать ложные знания 2, 送礼/nреподнести подарки 1，罚 站/cтоять в наказание 1 с негативной окраской появляется у китайцев в связи с определенной общественной реальностью в Китае. А реакции у русских испытуемых отсутствуют.

6. Положительная оценка. Для китайцев Учитель/ 教师 ассоциируется с 神圣/священным 5, 和蔼/ дружелюбным 3, 无私/бескорыстным 3, 严肃/ceрьезным 2, для русских учитель - с любимым 2, хорошим 2, прекрасным 1, сердечным 1.

7. Отрицательная оценка. Для китайцев 教师/Учитель, прежде всего, ассоциируется с 辛苦/mяжелым 7, для русских - с злым 2. В ассоциативном поле у китайцев существуют слова-реакции 烦 Nраздражающий 2, 累/усталый 2 с негативной оценкой. У русских - плохой 2.

8. Локус. В ассоциативном поле слова-стимула «Учитель/教师» у китайских испытуемых появилось немалое количество слов-реакций 学校/универcumem 18，教室/аудитория 4, 哈师大ХХарбинский педагогический университет 2, а подобные у русских отсутствуют. Таким образом, ассоциаты, связанные с локусом занимают у китайцев определенное место в представлении об учителе.

\section{Выво $\Delta ы$}

В результате сравнения и анализа данных мы можем сделать выводы, что:

Во-первых, об образе учителя у русских и китайцев имеются не только тождественные представления, но и специфические. Сходство заключается в существовании общего понятия об одной и той же профессии, различия связаны с разным менталитетом и культурными стереотипами.

Во-вторых, китайцы рассматривают учителя, прежде всего, как того, кто учит. Для русских учитель - в первую очередь, это учитель истории.

B-третьих, китайцы уделяют особое внимание людям 
и предметам, связанным с учителем и профессиональной деятельностью. А русские обращают внимание на конкретного специалиста.

Стоит отметить, что китайцы имеют уникальное представление об учителе как о 蜡烛/свече 8, 红烛/красной свече 2, 桃李/персиковом дереве и сливовом дереве 2, 灵 魂工程师/инженере человеческой души 1. Эти ассоциации отражают культурную специфику в языковом сознании китайцев. В русском языковом сознании учитель - мучитель 3. Нужно отметить, что китайцы и русские в целом имеют положительное отношение к учителю, одновременно отмечаются некоторые реакции с отрицательным оттенком, связанные с реальным состоянием современного общества обеих стран.

\section{ЛИТЕРАТУРА}

1. Зиброва С.В. Профессиональное сознание: репрезентация и образ профессии (социально-философский анализ). Автореф. ... к. философ. н. Красноярск, 1999. C. 18.

2. Тарасов Е.Ф. Межкультурное общение - новая онтология анализа сознания / Под ред. Н.В. Уфимцевой // Этнокультурная специфика языкового сознания. - М.: Институт языкознания РАН, 1996. С. 7-22.

3. Тарасов Е.Ф. Языковое сознание - перспективы исследования (предисловие) // Языковое сознание: содержание и функционирование. ХІІІ Международный симпозиум по психолингвистике и теории коммуникации. М., 2000. С. 3.

4. Тарасов Е.Ф. Предисловие // Образ России: извне и изнутри: сборник статей / Под ред. Е.Ф. Тарасов (ответственный редактор), Е.А. Аршавской, Н.В.Уфимецева. Калуга: Издательство «Эйдос», 2008. 316 с.

5. Уфимцева Н.В. Языковое сознание: динамика и вариативность// Институт языкознания. М.:РАН, 2011. 252 с.

6. Уфимцева Н.В. Тарасов Е.Ф. Проблемы изучения языкого сознания // Вопросы психолингвист.

○ Цзя Шуюе (1041487637@qq.com), Янь Лэй (yl19920310@126.com).

Журнал «Современная наука: актуальные проблемы теории и практики»

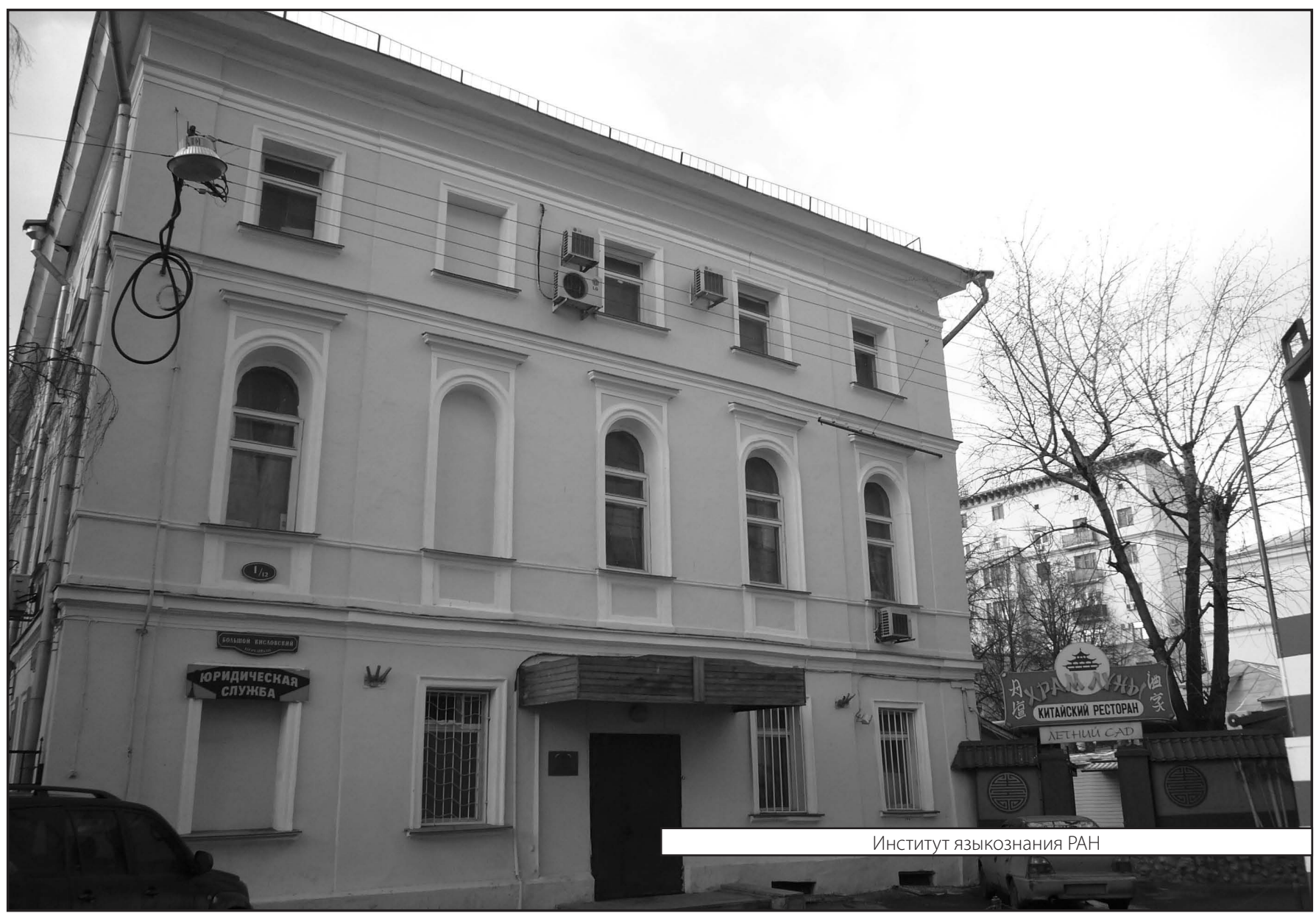

